\title{
IoT based Industry Automation using Arm7
}

\author{
Esha Gandotra ${ }^{1}$, Suvidha Kohli ${ }^{2}$, Shavaya Gupta ${ }^{3}$, Rohan Slathia ${ }^{4}$ \\ Model Institute of Engineering and Technology, Jammu, J\&K, India ${ }^{1,2,3,4}$
}

\begin{abstract}
Automation is the current need of industries. There are number of technologies that are growing to achieve the good automation in the plant. Industries have been automated with machines that allow for fully automated tasks without or little manual intervention. Well here we propose an internet based industry automation system that allows a single industry operator to control industry appliances with ease using ARM7 processor and IOT. Our proposed system allows for automation of industrial loads to achieve automation over internet. We use IOT for the web serve interface and ARM7 processor to process and run circuit loads. User is allowed to send commands for machines/ load switching over internet using IOT from anywhere in the world over internet. The ARM7 processor captures these commands by internet over wifi connector. Now the ARM7 processes received data to extract user commands. After getting commands it displays it on LCD display. Also it switches the loads on/off based on received commands to achieve user desired output. The system thus achieves industry automation over IOT using ARM7 processor.
\end{abstract}

Keywords: Arm7, Internet of things (IOT), GSM, LCD, Wifi.

\section{INTRODUCTION}

Our project automation of industries using ARM7 processor is based on IOT. IOT can be described as connecting everyday objects like smart-phones, Internet TVs, sensors and actuators to the internet where the devices are intelligently linked together enabling new forms of communication between things and people and between things themselves. IOT can be realized in three paradigns - Internet oriented (middlewire), things oriented (sensors) and semantic oriented (knowledge). With the advent of technology [2][6]. the world around us is getting automated. Automated systems are favored over manual systems, as they are energy efficient and minimize the need for tedious manual labour and make tasks easier and faster, leading to more industrial output. Here we propose an internet based industry automation system that allows a single industry operator to control industry appliances with ease using ARM7 processor and IOT. Our proposed system allows for automation of industrial loads to achieve automation over internet. We use IOT for the web serve interface and ARM7 processor to process and run circuit loads. User is allowed to send commands for machines/ load switching over internet using IOT from anywhere in the world over internet. The ARM7 processor captures these commands by internet over wifi connector. Now the ARM7 processes received data to extract user commands [4]. After getting commands it displays it on LCD display. Also it switches the loads on/off based on received commands to achieve user desired output. The system thus achieves industry automation over IOT using ARM7 processor.

\section{MOTIVATION}

The new age of technology has redefined communication. Most people nowadays have access to mobile phones and thus the world indeed has become a global village. At any given moment, any particular individual can be contacted with the mobile phone. But the application of mobile phone cannot just be restricted to sending SMS or starting conversations. New innovations and ideas can be generated from it that can further enhance its capabilities. Technologies such as Infra-red, Bluetooth, etc which has developed in recent years goes to show the very fact that improvements are in fact possible and these improvements have eased our life and the way we live. Remote management of several home and office appliances is a subject of growing interest and in recent years we have seen many systems providing such controls.

\section{LITERATURE REVIEW}

The literature related to the research topic has been reviewed for last twenty years in order to find out work carried out by various researchers. There are many systems for remote monitoring and control designed as commercial products or experimental research platforms. It is noticed that most of the research carried out belongs to the following categories: $\square$ Internet based Monitoring using Servers, GRR modems, etc. with different approaches. $\square$ GSMSMS protocols using GSM module individually or in combination with Internet technologies $\square$ Monitoring using Wireless Sensor Networks. $\square$ Wireless Monitoring using Bluetooth, WiFi, Zigbee and RF(radio frequency). $\square$ Applications have varied widely like Home Automation, Security Systems, Bio-medical applications, Agriculture, Environment, Reservoir, Bridge health monitoring, etc. 


\section{PROBLEM IDENTIFICATION}

Technology has advanced so much in the last decade or two that it has made life more efficient and comfortable. The comfort of being able to take control of devices from one particular location has become imperative as it saves a lot of time and effort. Therefore there arises a need to do so in a systematic manner which we have tried to implement with our system. The system we have proposed is an extended approach to automating a control system.

\section{BLOCK DIAGRAM}

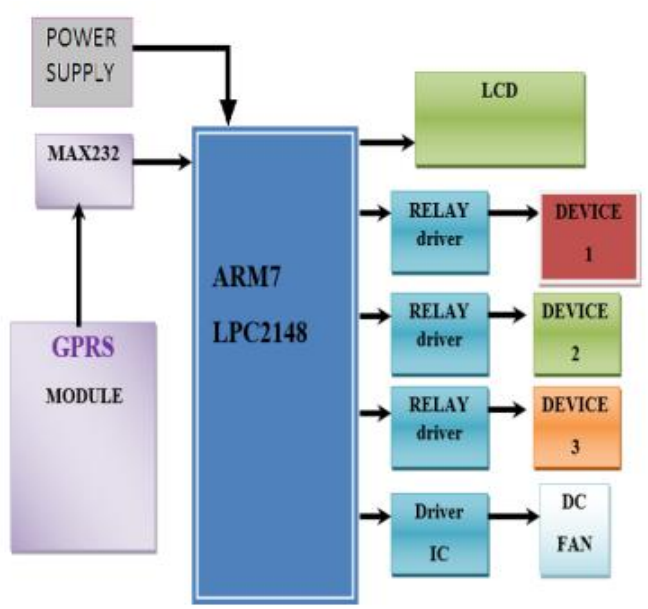

Our proposed model consists of a power supply unit which gives the required voltage to ARM7 processor.

User sends the command for switching to the ARM7 processor through internet using IOT. ARM7 processor processes received data to extract user commands. After getting commands it displays it on LCD. Then, it switches the load on/off based on received commands to achieve user desired output.

\section{WORKING}

The block diagram is a illustration of how we have implemented out project and the various parts involved in it. From the above representation, power supply block gives the required voltage of $5 \mathrm{~V}$ to ARM7 processor and the led glows indicating that the system is ready for use. Then the user is allowed to send the commands for machine/load switching over internet using IOT interface from anywhere in the world over internet [7]. The ARM7 processor now captures these commands by internet over wifi connector. Now the ARM7 processes received data to extract user commands. After getting commands it displays them on LCD display. Also, it switches the load on/off based on received commands to achieve user desired output [194-195]. The relay driver is used to drive the relay circuits which switches the different appliances connected to the interface [386-387]. The input from the user is feed to ARM7 and processed to operate respective task semi autonomously and autonomously. Assuming, that the control unit is powered and operating properly, the process of switching/controlling a device connected to the interface will proceed through the following steps-

- The remote user sends the commands to the receiver.

- GSM receiver receives messages sent from the user over internet.

- GSM receiver decodes the sent messages and sends the commands to the microcontroller (ARM7).

- Microcontroller issues commands to the appliances and the devices connected will be switched on/off.

\section{HARDWARE DESCRIPTION}

\section{- $\quad$ ARM7 LPC2148 Microcontroller}

ARM7 LPC21487 is one of the widely used microcontroller based on a 16-bit/32-bit ARM7TDMI-S CPU with realtime emulation and embedded support. LPC2148 is RISC based processor that uses fewer transistors than other typical processors. Hence it leads to low cost and low power consumption. In this work some sensors such as LM35 temperature sensor gives the analog data that need to be convert in to digital. Its 10-bit A/D converter provide digital output with respect to the voltage given by LM35 with conversion times as low as 2.44 us per channel. The power supply operating voltage range is from $3.0 \mathrm{~V}$ to $3.6 \mathrm{~V}$. The main reason behind selection of ARM7 is its support for uC/OS-II RTOS for real-time execution of tasks. Programming of is done using embedded C-Language with the help of Keil UV4 software tool. 


\section{FEATURES}

- 16-bit/32-bit ARM7TDMI-S microcontroller in a tiny LQFP64 package.

- $8 \mathrm{kB}$ to $40 \mathrm{kB}$ of on-chip static RAM and $32 \mathrm{kB}$ to $512 \mathrm{kB}$ of on-chip flash memory. (128-bit wide interface/accelerator enables high-speed $60 \mathrm{MHz}$ operation.

- In-System Programming/In-Application Programming (ISP/IAP) via on-chip boot (loader software. Single flash sector or full chip erase in $400 \mathrm{~ms}$ and programming of $256 \mathrm{~B}$ in $1 \mathrm{~ms}$.

- Embedded ICE RT and Embedded Trace interfaces offer real-time debugging with the (on-chip Real Monitor software and high-speed tracing of instruction execution.

- One or two (LPC2141/42 vs. LPC2144/46/48) 10-bit ADCs provide a total of 6/14( s per channel

- Two 32-bit timers/external event counters (with four capture and four compare( channels each), PWM unit (six outputs) and watchdog.

- $\quad$ Low power Real-Time Clock (RTC) with independent power and $32 \mathrm{kHz}$ clock input.(

\section{- RELAY}

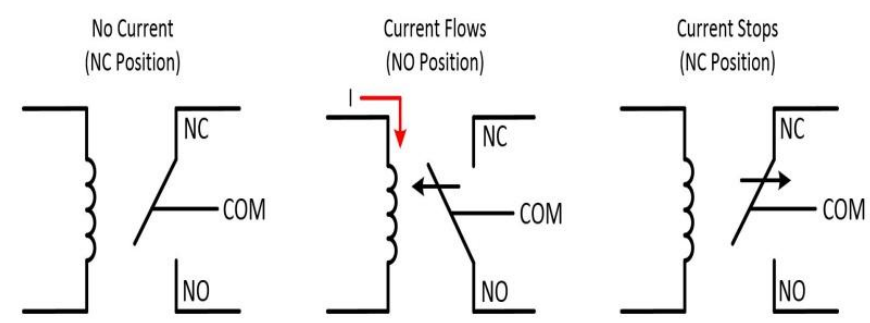

The relay driver is used to isolate both the controlling and the controlled device. The relay is an electromagnetic device, which consists of solenoid, moving contacts (switch) and restoring spring and consumes comparatively large amount of power. Hence it is possible for the interface IC to drive the relay satisfactorily. To enable this, a driver circuitry, which will act as a buffer circuit, is to be incorporated between them. The driver circuitry senses the presence of a "high" level at the input and drives the relay from another voltage source. Hence the relay is used to switch the electrical supply to the appliances. From the figure when we connect the rated voltage across the coil the back emf opposes the current flow but after the short time the supplied voltage will overcome the back emf and the current flow through the coil increase. When the current is equal to the activating current of relay the core is magnetized and it attracts the moving contacts. Now the moving contact leaves from its initial position denoted "(N/C)" normally closed terminal which is a fixed terminal. The common contact or moving contact establishes the connection with a new terminal which is indicated as a normally open terminal "(N/O)". Whenever, the supply coil is withdrawn the magnetizing force is vanished. Now, the spring pulls the moving contact back to initial position, where it makes a connection makes with $\mathrm{N} / \mathrm{C}$ terminal. However, it is also to be noted that at this time also a back emf is produced. The withdrawal time may be in microsecond, the back emf may be in the range of few kilovolts and in opposite polarity with the supplied terminals the voltage is known as surge voltage. It must be neutralized or else it may damage the system.

\section{- GSM TECHNOLOGY}

GSM is a global system for mobile communication .GSM is an international digital cellular telecommunication. The GSM standard was released by ETSI (European Standard Telecommunication Standard) back in 1989. The first commercial services were launched in 1991 and after its early introduction in Europe; the standard went global in 1992. Since then, GSM has become the most widely adopted and fastest-growing digital cellular standard, and it is positioned to become the world's dominant cellular standard. Today's second-generation GSM networks deliver high quality and secure mobile voice and data services (such as SMS/ Text Messaging) with full roaming capabilities across the world. GSM platform is a hugely successful technology and as unprecedented story of global achievement. In less than ten years since the first GSM network was commercially launched, it become, the world's leading and fastest growing mobile standard, spanning over 173 countries. Today, GSM technology is in use by more than one in ten of the world's population and growth continues to sour with the number of subscriber worldwide expected to surpass one billion by through end of 2003.The Global System for Mobile Communication (GSM) network is a cellular telecommunication network with a versatile architecture complying with the ETSI GSM 900/GSM 1800 standard. Siemen's implementation is the digital cellular mobile communication system D900/1800/1900 that uses the very latest technology to meet every requirement of the standard.

\section{- LCD}

Liquid crystal display a type of display used in digital watches and many portable computers. LCD displays utilize two sheets of polarizing material with a liquid crystal solution between them. An electric current passed through the liquid 
crystal causes the crystal to align so that light cannot pass through them. Each crystal, therefore, is like a shutter, either allowing light to pass through or blocking the light. They are usually controlled by microcontroller. They make complicated equipment easier to operate. It runs off a $5 \mathrm{~V}$ DC supply and only needs about $1 \mathrm{~mA}$ of current. The display contrast can be varied by changing the voltage into pin 3 of the display usually with a trim pin.

\section{ADVANTAGES}

- It can be used in home security, offices and industries.

- The range of device is very high.

- Large no. of appliances can be connected.

- Simple operation and easy to use.

- We can also use this system for controlling heavy machineries in industries.

\section{CONCLUSION}

The project we have undertaken has helped us gain a better perspective on various aspects related to our course of study as well as practical knowledge of electronic equipments and communication. The extensive capabilities of this system are what make it so interesting. From the convenience of a simple cell phone, a user is able to control and monitor virtually any electrical devices. This makes it possible for users to rest assured that their belongings are secure and that the television and other electrical appliances was not left running when they left the house to just list a few of the many uses of this system. The end product will have a simplistic design making it easy for users to interact with. This will be essential because of the wide range of technical knowledge that industries have.

\section{FUTURE ASPECTS}

The future implications of the project are very great considering the amount of time and resources it saves. The project we have undertaken can be used as a reference or as a base for realizing a scheme to be implemented in other projects of greater level such as weather forecasting, temperature updates, device synchronization, etc. The project itself can be modified to achieve a complete Home Automation System which will then create a platform for the user to interface between himself and his household. In future the system will be small box combining the microcontroller and GSM Module. The hardware will be self contained and cannot be prone to electric failure. This appliance will have its own encapsulated UPS and charging system. This system is developed for mobile reporting application only. It also can be interfaced to computer system to record and process data base.

\section{ACKNOWLEDGEMENT}

Every project big or small is successful largely due to the effort of a number of wonderful people who have always given their valuable advice or lent a helping hand. We sincerely appreciate the inspiration; support and guidance of all those people who have been instrumental in making this project a success. We would like to express special thanks of gratitude to our mentor Mrs. Priya Manhas who gave us the golden opportunity to do this wonderful project on the topic "IOT based Automation of Industries using ARM7", which also helped us in doing a lot of Research and we came to know about so many new things. At this juncture, we feel deeply honored in expressing our sincere thanks to our HOD Mrs. Taru Mahajan for making the resources available at right time and providing valuable insights leading to the successful completion of our project. We would also like to thank all the faculty members of MIET JAMMU for their critical advice and guidance without which this project would not have been possible. Last but not the least we place a deep sense of gratitude to our family members and friends who have been constant source of inspiration during the preparation of this project work.

\section{REFERENCES}

[1] K. Bromley, M. Perry, and G. Webb. "Trends in Smart Home Systems, Connectivity and Services", www.nextwave.org.uk, 2003.

[2] A. R. Al-Ali and M. Al-Rousan, "Java-based home automation system", IEEE Transactions on Consumer Electronics, vol. 50, no. 2, pp. 498- 504, 2004.

[3] N. Sriskanthan, F. Tan and A. Karande, "Bluetooth based home automation system", Microprocessors and Microsystems, Vol. 26, no. 6, pp. $281-289$, 2002.

[4] H. Ardam and I. Coskun, "A remote controller for home and office appliances by telephone", IEEE Transactions on Consumer Electronics, vol. 44, no. 4, pp. 12911297,1998

[5] T. Baudel and M. Beaudouin-Lafon, "Charade: remote control of objects using free-hand gestures", Communications of the ACM, vol. 36, no. 7, pp. 28-35, 1993.

[6] T. Saito, I. Tomoda, Y. Takabatake, J. Ami and K. Teramoto, "Home Gateway Architecture And Its Implementation", IEEE International Conference on Consumer Electronics, pp. 194-195, 2000.

[7] N. Kushiro, S. Suzuki, M. Nakata, H. Takahara and M. Inoue, "Integrated home gateway controller for home energy management sy stem", IEEE International Conference on Consumer Electronics, pp. 386-387, 2003 